\title{
The influence of Coordination on the Performance of Plant Turnaround Maintenance through Team Alignment in Malaysian Process-Based Industry
}

\author{
Jalal ud Din Akbar*, Zulkipli Ghazali \\ Department of Management and Humanities, 32610 Universiti Teknologi PETRONAS Malaysia
}

\begin{abstract}
The plant turnaround maintenance is a maintenance activity in which the machinery and equipment of the plant are shut down for repairing the worn out parts or installing new machinery. The event is costly and time consuming requiring a competent maintenance management. The large work activities of the event requires the services of large number of people. These people work in congested areas which might cause conflicts among the members and requires team alignment. It helps in attaining high performance of the event and the company. The current study uses survey approach for the data collection from oil \& gas refining companies, petrochemical plants, cement plants, palm oil refineries and electric power generating plants. The simple random sampling technique was used for collecting the data. The data collected from 31 out of 96 companies yields an acceptable response rate of $32 \%$. The empirical results of the current study shows that the performance of the plant turnaround maintenance increases with coordination and team alignment in plant turnaround maintenance.
\end{abstract}

\section{Introduction}

The large process-industries of oil and gas refineries, cement plants, petrochemical plants and palm oil plants convert huge amounts of raw materials to end products. using various chemical, physical and mechanical processes (Ghazali, 2010). The economical and safe availability of the process-plants and its reliability is achieved through plant turnaround maintenance. It helps in lowering the risk of unscheduled or catastrophic failures (Ghazali, 2010; Obiajunwa, 2007).

Turnaround maintenance is carried out to avoid breakdowns of the equipment causing loss of productivity and finances (Hameed \& Khan, 2014). The plant is revitalized, improve, modified and maintained through turnaround maintenance (Ghazali, 2010). The turnaround maintenance is done for the equipment, which otherwise cannot be repaired on an emergency basis. It requires both time and large number of maintenance personnel during turnaround shutdown (Duffuaa \& Ben Daya, 2004; Hameed \& Khan, 2014). So well planning techniques are made for doing the right job by the right person at the right time to achieve the objectives of the event (Duffuaa \& Ben Daya, 2004; Obiajunwa, 2007). The safety of the workers, materials, substances, tools, and equipment are well planned for the turnaround event (Duffuaa \& Ben Daya, 2004; Obiajunwa, 2007). It helps the process-companies to maintain or sustain their production capacity significantly over long period of time (Pokharel \& Jiao, 2008).

The previous research on turnaround maintenance shows that even the planning for the turnaround maintenance is carried out with outmost care, yet one out of four turnaround maintenance events fails. Furthermore, around $80 \%$ of the turnaround events do not achieve one or more of the performance indicators set by the turnaround maintenance teams. One of the possible reasons includes the team's inability and misalignment to work according to the plans to achieve the turnaround objectives (Shirley, 2012).

Therefore, the current study focuses on the coordination and team alignment of the human resource for achieving performance of the turnaround maintenance at an acceptable level. Hence, the objectives set for the current study are to investigate the impact of the coordination on the plant turnaround maintenance performance and

\footnotetext{
* Corresponding author: jalaluddin77@gmail.com
} 
To examine the mediation of team alignment between coordination and plant turnaround maintenance performance.

\section{Literature Review}

In the production and manufacturing plants, the damaged, worn out and malfunction parts are maintained and replaced through inspection, overhaul, modification and installation of new parts and equipment to increase the equipment operating capacity and running time. The machinery and plant equipment are the backbone of the process-industries and incur loses, if the equipment is not fully functional on time (Ghazali, 2010).

The time required for the planning, scheduling, allocation of the budget and sequencing of the work activities according to the time scheduled of the event is very long (Ghazali, 2010). A lot of resources have to be made available on site before the turnaround execution. These resources includes maintenance person, specialists, technicians, and experts from contractors (Ghazali, 2010; Lenahan, 1999; Raoufi \& Fayek, 2014).

The coordination and control of the event is very important. The event management organizes financial resources and the large number of people to carry voluminous activities in congested areas of the process-plants. The low space and large number of people usually causes conflicts and disputes among the workers, which requires team alignment. It helps to resolve the conflicting issues among the worker, mitigate the risk of falling behind the time schedule, achieve the high quality work and performance of the event (Ghazali, 2010).

The above discussion highlight the importance of the coordination of the resources for the performance of the turnaround event and dealing the conflict among the turnaround maintenance workers through team alignment.

\subsection{Coordination}

The organizing of tasks, people, and organizational resources are the coordination function of management. To achieve the defined organizational goals, the managers need to form appropriate arrangement within the organization (Bartol, Tein, Mathews, \& Sharma, 2008). The manager skillful human resource, technology, and team oriented facilities to accomplish the planned goals and objectives (Campling, Poole, Wiesner, \& Schernerhorn, 2008; Robbins, Bergman, Stagg, \& Coulter, 2009). The coordination of the activities has to match with the company's planning (Williams \& McWilliams, 2010).

By successful utilization of organizational resources, the turnaround maintenance goals are attained within the allocated time and budget. The management function of coordination (Campling et al., 2008; Robbins et al., 2009) is utilized all through different phases of turnaround maintenance. The planning and organizing are more required in planning phase and initiating phase though leading and control is more needed in execution stage than other phases (Ghazali, 2010).

The turnaround needs a lot more people than the normal maintenance work to mitigate risks (Raoufi \& Fayek, 2014). These huge manpower resources are required on a temporary basis (Ghazali, 2010; Pokharel \& Jiao, 2008). The event is composed of interrelated activities performed at the same time by a large number of the workforce at different levels of the plant. The congested area with a large number of the workforce has causes accidents, errors, confusions, and conflicts (Ghazali, 2010).

It is an engineering activity, consists of four phases i.e., initiation, preparation \& planning, execution, and termination. The actual phase of execution has very short time period for its completion and the highest number of people. The large number of work activities and people needs coordination in turnaround through efficient and effective management process in meeting the objectives (DeBakey, Samman, Sulaiman, Blanchard, \& Edmundson, 2007; Ghazali, 2010). The work activities involved in the execution phase is many folds higher than the normal maintenance operations of the business. The strict rule of target achievement prevails during the execution phase (Ghazali, 2010).

The availability of all the required tools, spares and equipment are organized and coordinated at the right place with the right team (Lenahan, 1999) to achieve the turnaround execution goals (Raoufi \& Fayek, 2014). The successful accomplishment of this event in terms of time, cost and quality is vital to the competitive edge and profitability of the company. For these reasons, it is important for such companies to have a sound process of coordination and alignment for the turnaround maintenance (Duffuaa \& Ben-Daya, 2009). 


\subsection{Alignment}

The alignment is the setting of the core goals and objectives of the organization to meet the desired goals and objectives (Alsudiri, Al-Karaghouli, \& Eldabi, 2013). In the modern organizations, the alignment is achieved through the organizational strategy (Daft, 1995). In general, the high performance is achieved through alignment with the unfavourable settings and strategy type (Gupta, 2011). To align the organization with the environment; a comparatively durable arrangement of planned behaviour is required (Miles, Snow, Meyer, \& Coleman, 1978).

For enhancing alignment among various departments of an organization, there are many methods and techniques available to achieve it. It depends on the degree of integration required, the difficulty of achieving it in a given situation and cost of the alignment resources. The use of complex integration tools for alignment purposes might increase the cost of the organization. (Child, 1984).

The literature recommends that alignment had a positive impact on performance, whereas misalignment is likely to damage the efficiency of the project performance (Alsudiri et al., 2013). In plant turnaround maintenance, the turnaround manager carefully align the turnaround teams with the turnaround objectives and organizational goals and objectives as a whole (Alsudiri et al., 2013).

The people in the team, work as a single social unit in an organization with common responsibilities. The team achievement depends on the member's capacity to communicate, their level of obligation to the work outlines and the attainment of the objectives (Nyberg, Nilsson, \& Skinstad, 2009). The successful organizations utilize business deals that have cooperative teamwork through integration and alignment (Chonko \& Weeks, 2008).

Venkatraman (1989) presented six different methods of using alignment in the academics i.e., mediation, moderation, matching, gestalt, profile deviation and co-variation (Ismail \& King, 2014). The current study uses mediation approach of alignment. The empirical testing of the mediation perspective of alignment carried out by Bergeron and Raymond (1995) and Teo and King (1996) found the positive relationship between the predictor and dependent variables (Kefi \& Kalika, 2005). Other researchers like Chan (1992), Chan, Huff, Barclay, and Copeland (1997), Sabherwal and Chan (2001) and Cragg, King, and Hussin (2002) considers the mediation approach of alignment an excellent approach in terms of explaining the results and conclusions (Taskin \& Verville, 2010).

\subsection{Performance}

The success of the organization is determined by the organizational performance (Croteau, Solomon, Raymond, \& Bergeron, 2001). In the case of the plant turnaround maintenance, the performance indicators includes time, cost, safety, health, quality and environment. These performance measures and indicators are set in the preparation and planning phase of the turnaround maintenance (Lenahan, 1999).

The large number of people for huge work activities poses a risk of not meeting the already set measures of performance (Lenahan, 1999). Therefore, the management takes careful measures to monitor the progress and development at each phase with time intervals to know the challenges facing in achieving the performance parameters of the plant turnaround maintenance. The coordination, team alignment and knowledge of team members about their roles and responsibilities helps in achieving the set goals and objectives (Ben-Daya, Ait-Kadi, Duffuaa, Knezevic, \& Raouf, 2009).

The management functions of coordination is all used in these four phases of plant turnaround maintenance with varying degree. The coordination is more used in the initiation and planning phases of the plant turnaround maintenance and less used in the execution and termination phases of the turnaround maintenance. The coordination of the human and financial resources prior to the actual execution of the event is extremely important and necessary. For this reason, the current study will explore the influence of coordination on the plant turnaround performance through the mediation of team alignment.

\section{Research Methodology}

The current study adapted survey questionnaires for collection of the primary data. The survey items are adapted from the literature. The items are checked thoroughly for their clarity and easy understanding. The target population for current study is the process-based companies of Malaysia, which includes oil \& gas refining companies, petrochemical plants, cement plants, palm oil refineries and electric power generating plants. These process-companies carry turnaround maintenance. The target respondents include turnaround maintenance engineers and other technical staff. The survey questionnaires were distributed to around ninety six companies. 
Thirty nine companies responded. Only thirty one companies' responses were found to be valid for data analysis yielding a response rate of $32 \%$.

The sample random sampling technique is used for selection of the samples from the population which is good for selecting, distribution and collection of survey questionnaires due to its low level of biasness and easy interpretation of the research results. The current study employs 5-point Likert scale, stating from never to always (never, rarely, as and when necessary, often and always). The current study use SPSS version 22 for the analysis of the data collected.

\section{Results and Discussion}

\subsection{Descriptive Statistics and Correlations}

The descriptive statistics for the variables of coordination, team alignment and performance are shown below in table 1 . The mean value shows the central tendency of the data collected, whereas the standard deviation shows the variance or dispersion of the data from the mean. The mean values of coordination, team alignment and performance are $\mu=4.24, \mu=4.29$ and $\mu=4.15$ respectively. It shows that often implement and follow the instructions of coordination, alignment and performance. Similarly the standard deviation for coordination, team alignment and performance are $\sigma=0.29, \sigma=0.26$ and $\sigma=0.26$ successively. The standard deviation results shows that the coordination data has high dispersion as compared to team alignment and turnaround maintenance performance.

The correlation also called bivariate correlation shows the relationship between two variables. The value of the coefficient of the correlation shows the strength and weakness of the relationship, whereas the signs shows the direction of the relationship. The positive relationship is represented by plus (+) sign and the negative relationship is represented by minus (-) sign. The value of correlation between coordination and alignment is $\mathrm{r}=.912$, coordination and performance is $r=.657$ and alignment and performance is $r=.777$. All the coefficient values of the correlation between the variables are positive, whereas the coefficient value of the correlation between coordination and alignment is strong as compared to the other variables.

Table 1.Descriptive Statistics and Correlation

\begin{tabular}{lllll}
\hline & Mean & SD & Coordination & Alignment \\
\hline Coordination & 4.24 & 0.29 & 1.00 & \\
Alignment & 4.29 & 0.26 & $.912^{* *}$ & 1.00 \\
Performance & 4.15 & 0.26 & $.657^{* *}$ & $.777^{* *}$ \\
\hline$* *$ Correlation is significant at the 0.01 level (2-tailed). & & & 1.00 \\
\hline
\end{tabular}

\subsection{Regression Analyses}

The regression analysis is used to check the influence of one variable on two or more than two variables. It is used to know the degree of influence of predictor or independent variable on the dependent variable (Hair, Anderson, Tatham, \& William, 1998). The regression analysis for mediation consists of four steps (Baron \& Kenny, 1986). The details of each step is as follows.

\subsection{1 .Coordination verses Performance}

The detail of this regression analysis is given in the table 2 . The influence of the coordination on performance is $\beta=0.594$, $t$-value $=4.691$ and $p<0.01$ showing the significance at 0.001 confidence interval. The value of $R$-square is $\mathrm{R} 2=0.431$. The $\mathrm{R}$-square explains the dependent variable by the independent variable. In this case, the coordination explains about $43 \%$ of performance of the plant turnaround maintenance. Hence, from the above results the first objective is achieve which is to investigate the impact of coordination on the performance of the plant turnaround maintenance. 
Table 2. Coordination verses Performance

\begin{tabular}{lllll}
\hline \multicolumn{5}{c}{ Performance } \\
\hline & Beta Value & R Square & T Value & Significance Value \\
Coordination & .594 & .431 & 4.691 & .000 \\
\hline
\end{tabular}

The model for coordination verses performance is as follows in figure 1 .

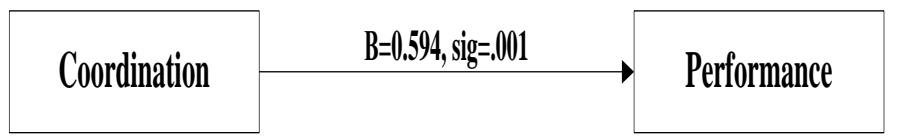

Figure 1. Coordination verses Performance

\subsubsection{Coordination verses Alignment}

The detail for this step of the regression analysis is given in table 3 . The beta value for the influence of the coordination on performance is $\beta=0.830, t$-value $=12.009$ and $\mathrm{p}<0.01$ showing the significance at 0.001 confidence interval. The value of $\mathrm{R}$-square is $\mathrm{R} 2=0.833$, which means that coordination explains about $83.3 \%$ of team alignment in the plant turnaround maintenance.

Table 3. Coordination verses Alignment

\begin{tabular}{lllll}
\hline & \multicolumn{4}{c}{ Alignment } \\
\hline & Beta Value & R Square & T Value & Significance Value \\
Coordination & .830 & .833 & 12.009 & .000 \\
\hline
\end{tabular}

The model for coordination verses alignment is given below in figure 2 .

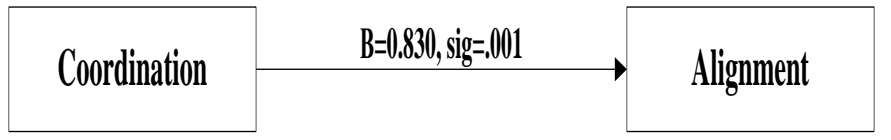

Figure 2. Coordination verses Alignement

\subsubsection{Alignment verses Performance}

The detail for this step of the regression analysis is given in Table 4 . The beta value for the influence of the alignment on performance is $\beta=0.773, t-v a l u e=6.651$ and $p<0.01$ showing the significance at 0.001 confidence interval. The value of $\mathrm{R} 2=0.604$, which means that team alignment explains about $60.4 \%$ of performance in the plant turnaround maintenance.

Table 4. Alignment verses Performance

\begin{tabular}{lllll}
\hline & \multicolumn{5}{c}{ Performance } \\
\hline & Beta Value & R Square & T Value & Significance Value \\
Alignment & .773 & .604 & 6.651 & .000 \\
\hline
\end{tabular}

The model for alignment verses performance is given below in the figure 3 .

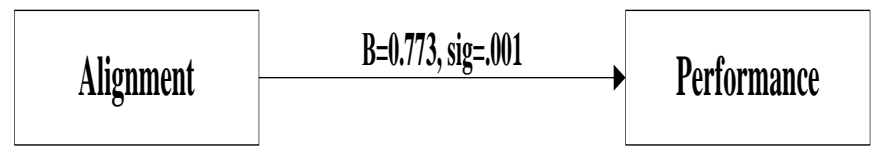

Figure 3. Alignment verses Performance

\subsubsection{Coordination verses Performance: Mediation of Team Alignment}

The fourth step is consists of a mediating variable of team alignment and is shown in the table 5 . The beta value for the impact of coordination on the performance is $\beta=-0.283, t=-1.099$ and $p<0.281$, which is non-significant. The beta value for the influence of alignment on performance is $\beta=1.056, t=3.733$ and $p<0.001$, which is significant. The results shows that coordination has no direct influence on the performance of the plant turnaround maintenance whereas through the team alignment, the coordination has influence on the performance of the plant turnaround maintenance. In this case, the influence of the coordination on the performance of the plant turnaround maintenance is fully mediated by team alignment. The value of $\mathrm{R}$-square is $\mathrm{R} 2=0.62$, which means that coordination explains $62 \%$ of the performance of the plant turnaround maintenance through team alignment. 
The R-square value for the direct influence of coordination on the performance of plant turnaround maintenance without using team alignment as mediator is $\mathrm{R} 2=0.431$. Whereas the $\mathrm{R}$-square value for the impact of coordination on the performance of the plant turnaround maintenance through team alignment is $\mathrm{R} 2=0.62$. It means that, the R-square value increases with the use of mediation and the coordination explains $62 \%$ of the performance of the plant turnaround maintenance. Hence, from the above results the second objective is achieve which is to know the mediation of team alignment between coordination and plant turnaround maintenance performance.

Table 5. Coordination verses Performance: Mediation of Team Alignment

\begin{tabular}{lllll}
\hline & \multicolumn{3}{c}{ Performance } \\
\hline & Beta Value & R Square & T Value & Significance Value \\
Coordination & -.283 & & -1.099 & .281 \\
Alignment & 1.056 & .620 & 3.733 & .001 \\
\hline
\end{tabular}

The model for coordination verses performance through team alignment is given below in figure 4 .

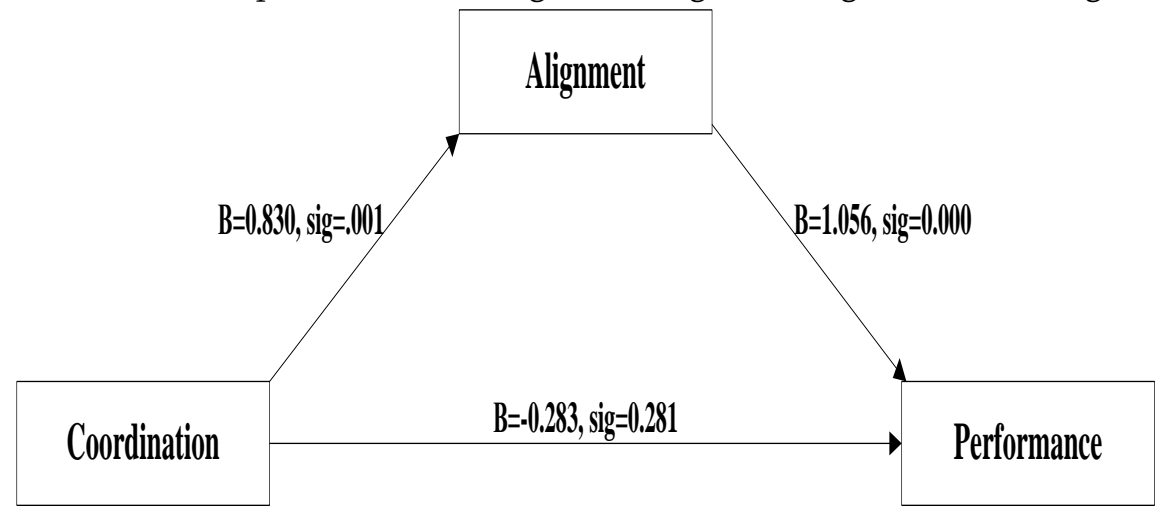

Figure 4. . Coordination verses Performance: Mediation of Team Alignment

\section{Conclusion}

The paper illustrate the importance of the coordination of the resources in the plant turnaround maintenance. The team alignment is equally important for the organizing of the useful resources both in terms of finances as well human resource. The empirical data shows that the performance of the plant turnaround maintenance increases with the coordination and the team alignment. The previous literature also considers the coordination of resources for organizations and projects very important. The current research supports the previous literature.

As the research paper is on the plant turnaround maintenance, therefore it will help the stakeholders of plant turnaround maintenance to understand the importance of the coordination and team alignment. Some of the beneficiaries of the current research would be the people of the plant turnaround maintenance. It includes turnaround maintenance supervisors, engineers, technicians, business owners, and government agencies for the benefits of employee's health, safety and the environment.

\section{Acknowledgment}

This work was supported by Universiti Teknologi PETRONAS.

Cost Center: 0153AA-E59

Project Title: Carbon Capture and Storage (Ccs) Implementation Criteria Index Via Interpretive Structural Modelling Of Stakeholders' Views

Project Leader: Dr. Muhammad Ridhuan Tony Lim Bin Abdullah

Co- Project Leader: Associate Professor Dr. Zulkipli B Ghazali 


\section{References}

Alsudiri, T., Al-Karaghouli, W., \& Eldabi, T. (2013). Alignment of large project management process to business strategy: A review and conceptual framework. Journal of Enterprise Information Management, 26(5), 596615.

Baron, R. M., \& Kenny, D. A. (1986). The moderator-mediator variable distinction in social psychological research: Conceptual, strategic, and statistical considerations. Journal of personality and social psychology, 51(6), 1173.

Bartol, K., Tein, M., Mathews, G., \& Sharma, B. (2008). Management: A Pacific Rim Focus (5th ed ed.). North Ryde,NSW: McGraw-Hill, Australia: McGraw-Hill.

Ben-Daya, M., Ait-Kadi, D., Duffuaa, S. O., Knezevic, J., \& Raouf, A. (2009). Handbook of maintenance management and engineering (Vol. 7): Springer.

Bergeron, F., \& Raymond, L. (1995). The contribution of IT to the bottom line: a contingency perspective of strategic dimensions. Paper presented at the ICIS.

Campling, J., Poole, D., Wiesner, R., \& Schernerhorn, J. (2008). Management, 3rd Asia-Pacific Edition. Milton, Queensland, Australia: John Wiley \& Sons Australia Ltd.

Chan, Y. E. (1992). Business strategy, information systems strategy, and strategic fit: Measurement and performance impacts.

Chan, Y. E., Huff, S. L., Barclay, D. W., \& Copeland, D. G. (1997). Business strategic orientation, information systems strategic orientation, and strategic alignment. Information systems research, 8(2), 125-150.

Child, J. (1984). Organization: A guide to problems and practice: Sage.

Chonko, L. B., \& Weeks, W. A. (2008). Alignment of Front-line Personnel: A Preliminary Attempt at Scale Development.

Cragg, P., King, M., \& Hussin, H. (2002). IT alignment and firm performance in small manufacturing firms. The Journal of Strategic Information Systems, 11(2), 109-132.

Croteau, A.-M., Solomon, S., Raymond, L., \& Bergeron, F. (2001). Organizational and technological infrastructures alignment. Paper presented at the System Sciences, 2001. Proceedings of the 34th Annual Hawaii International Conference on.

Daft, R. (1995). Organizational Theory and Design. Minnesota: West Publishing Co.

DeBakey, G., Samman, B., Sulaiman, S. M., Blanchard, K., \& Edmundson, D. (2007). Maximising Plant Productivity. Retrieved from http://www.ap-networks.com website: http://www.ap-networks.com/view-document/7maximizing-plant-productivityd44b.pdf?format=raw\&tmpl=component

Duffuaa, S. O., \& Ben-Daya, M. (2009). Turnaround Maintenance "Handbook of Maintenance Management and Engineering" (Vol. 7). London: Springer.

Duffuaa, S. O., \& Ben Daya, M. (2004). Turnaround maintenance in petrochemical industry: practices and suggested improvements. Journal of Quality in Maintenance Engineering, 10(3), 184-190.

Ghazali, Z. (2010). Organizational Context, Structure, and Performance of Plant Turnaround Maintenance in Malaysian Process-based Industries.

Gupta, B. (2011). A comparative study of organizational strategy and culture across industry. Benchmarking: An International Journal, 18(4), 510-528.

Hair, J. F., Anderson, R. E., Tatham, R. L., \& William, C. (1998). Black (1998), Multivariate data analysis: Upper Saddle River, NJ: Prentice Hall.

Hameed, A., \& Khan, F. (2014). A framework to estimate the risk-based shutdown interval for a processing plant. Journal of Loss Prevention in the Process Industries, 32, 18-29.

Ismail, N. A., \& King, M. (2014). Factors influencing the alignment of accounting information systems in small and medium sized Malaysian manufacturing firms. Journal of Information Systems and Small Business, 1(1-2), 120.

Kefi, H., \& Kalika, M. (2005). Survey of strategic alignment impacts on organizational performance in international European companies. Paper presented at the System Sciences, 2005. HICSS'05. Proceedings of the 38th Annual Hawaii International Conference on.

Lenahan, T. (1999). Turnaround management: Butterworth-Heinemann.

Miles, R. E., Snow, C. C., Meyer, A. D., \& Coleman, H. J. (1978). Organizational strategy, structure, and process. Academy of management review, 3(3), 546-562.

Nyberg, S., Nilsson, A., \& Skinstad, E. (2009). The connections between values alignment and teamwork: A case study.

Obiajunwa, C. (2007). Optimization of turnaround maintenance project implementation. RCOM A, 21.

Pokharel, S., \& Jiao, J. (2008). Turn-around maintenance management in a processing industry: A case study. Journal of Quality in Maintenance Engineering, 14(2), 109-122.

Raoufi, M., \& Fayek, A. R. (2014). Process Improvement for Power Plant Turnaround Planning and Management. Architecture, Engineering and Construction, 168.

Robbins, S., Bergman, R., Stagg, I., \& Coulter, M. (2009). Foundations of Management 3e. Frenchs Forest: NSW: Pearson.

Sabherwal, R., \& Chan, Y. E. (2001). Alignment between business and IS strategies: A study of prospectors, analyzers, and defenders. Information systems research, 12(1), 11-33. 
Shirley, P. (2012). Turnaround Excellence Through Organizational Transformation. Retrieved from http://www.apcanada.ca website: http://www.ap-canada.ca/download-document/22-turnaround-excellence-organizationaltransformation.html.

Taskin, N., \& Verville, J. (2010). An exploratory study on strategic alignment of enterprise systems and business strategies, performance, and flexibility. Paper presented at the Proceedings of 7th International Conference on Enterprise Systems, Accounting and Logistics (7th ICESAL 2010).

Teo, T. S., \& King, W. R. (1996). Assessing the impact of integrating business planning and IS planning. Information \& Management, 30(6), 309-321.

Williams, C., \& McWilliams, A. (2010). MGMT, 1st,'. South Melbourne: Cengage. 